\title{
MULTIFRACTAL ANALYSIS OF SEISMICALLY INDUCED SOFT-SEDIMENT DEFORMATION STRUCTURES IMAGED BY X-RAY COMPUTED TOMOGRAPHY
}

\author{
YOSHITO NAKASHIMA* and JUNKO KOMATSUBARA \\ National Institute of Advanced Industrial Science and Technology (AIST) \\ Geological Survey of Japan, Central 7, Higashi 1-1-1 \\ Tsukuba, Ibaraki 305-8567, Japan \\ *nakashima.yoshito@aist.go.jp
}

Received August 25, 2017

Accepted December 1, 2017

Published December 29, 2017

\begin{abstract}
Unconsolidated soft sediments deform and mix complexly by seismically induced fluidization. Such geological soft-sediment deformation structures (SSDSs) recorded in boring cores were imaged by X-ray computed tomography $(\mathrm{CT})$, which enables visualization of the inhomogeneous spatial distribution of iron-bearing mineral grains as strong X-ray absorbers in the deformed strata. Multifractal analysis was applied to the two-dimensional (2D) CT images with various degrees of deformation and mixing. The results show that the distribution of the iron-bearing mineral grains is multifractal for less deformed/mixed strata and almost monofractal for fully mixed (i.e. almost homogenized) strata. Computer simulations of deformation of real and synthetic digital images were performed using the egg-beater flow model. The simulations successfully reproduced the transformation from the multifractal spectra into almost monofractal spectra (i.e. almost convergence on a single point) with an increase in deformation/mixing
\end{abstract}

\footnotetext{
*Corresponding author.

This is an Open Access article published by World Scientific Publishing Company. It is distributed under the terms of the Creative Commons Attribution 4.0 (CC-BY) License. Further distribution of this work is permitted, provided the original work is properly cited.
} 
intensity. The present study demonstrates that multifractal analysis coupled with X-ray CT and the mixing flow model is useful to quantify the complexity of seismically induced SSDSs, standing as a novel method for the evaluation of cores for seismic risk assessment.

Keywords: Earthquake; Liquefaction; Multifractal; Sediment Deformation; X-ray CT.

\section{INTRODUCTION}

Water-saturated unconsolidated sediments with low bulk-density deposited at the shallow subsurface are readily fluidized and deformed by RayleighTaylor instability triggered by the mechanical vibration of earthquakes. 1 [1] Driven by buoyancy, the fluidized unconsolidated sediments deform and mix complexly to leave characteristic wavy and folding structures in the strata. ${ }^{4}[6$ These seismically induced soft-sediment deformation structures (SSDSs) are important records of past seismic activity and susceptibility, and the degree of deformation/mixing should be evaluated quantitatively for a seismic risk assessment of the site ${ }^{7,10}$

Multifractal analysis is a useful technique to quantify the complex deformation/mixing processes of fluids 1114,40 X-ray computed tomography (CT) provides quantitative two-dimensional (2D) images of geological samples with SSDSs. $\frac{15}{15}$ The spatial distribution of iron-bearing minerals (strong X-ray absorbers) as marker particles is recorded in the CT images. In the present study, multifractal analysis was applied to CT images of boring cores with various degrees of SSDSs to reveal the effects of the deformation/mixing intensity on the degree of multifractality (i.e. shape of $f(\alpha)$ spectra). Mixing simulations of sediment digital images were also performed using the egg-beater flow mode $\frac{14 \mid 16}{10}$ reproduce the effects of the deformation/mixing intensity on the multifractality.

\section{MULTIFRACTAL ANALYSES}

\subsection{CT Image Acquisition of Boring Cores with SSDSs}

The boring site, GS-INS-1, is located on an unconsolidated Quaternary flood plain of the downstream basin of the Tone River, Japan. The geographical and geological details of the boring site have been reported elsewhere $\frac{15}{15}$ The 2011 off the Pacific coast of Tohoku Earthquake hits the downstream basin of the Tone River. Sand "boiling" due to liquefaction followed by fluidization was observed on the ground surface at the site. Cylindrical boring cores (length $\approx 1 \mathrm{~m} \times 10$, diameter $\approx 64 \mathrm{~mm}$ ) were picked in the site after the earthquake and nondestructively analyzed by X-ray CT followed by destructive analyses (i.e. powder X-ray diffraction and X-ray fluorescence analyses). A specific core drilling method with air bubbles was employed to preserve the original SSDSs as much as possible. Vibration cone penetration tests were also performed after the 2011 off the Pacific coast of Tohoku Earthquake to measure the seismic susceptibility (soil rigidity) of the site.

A medical whole-body CT scanner (W2000, Hitachi Medical Co., Tokyo, Japan) was used.1517 Cores obtained from depths of 0 to $10 \mathrm{~m}$ were all imaged with the medical X-ray CT apparatus. However, the present study focused on two depths, i.e. $\approx 5 \mathrm{~m}$ and $\approx 10 \mathrm{~m}$ (Fig. 11), where various degrees of SSDSs were clearly observed. The groundwater level is approximately one meter beneath the ground surface, so that the cores from these depths were saturated with water. The voxel dimensions of the original reconstructed images are $0.31 \times 0.31 \times 0.5 \mathrm{~mm}^{3}$ $($ depth $\approx 5 \mathrm{~m})$ and $0.31 \times 0.31 \times 1.0 \mathrm{~mm}^{3}($ depth $\approx 10 \mathrm{~m}$ ) where $0.31 \mathrm{~mm}$ is the in-plane voxel dimension (i.e. horizontal resolution) and $0.5 \mathrm{~mm}$ and $1.0 \mathrm{~mm}$ are the slice thicknesses (i.e. vertical resolution). These voxel dimensions are much larger than the median diameter of the sediment grains $(\approx 0.2 \mathrm{~mm}){ }^{15}$ Therefore, the CT images obtained depict the heterogeneity of the spatial distribution of the grains (not the shape of each grain). The reconstructed raw CT images were further processed as follows. The original images were elongated in the vertical direction by 1.6 times (depth $\approx 5 \mathrm{~m}$ ) and 3.2 times (depth $\approx 10 \mathrm{~m}$ ) using the conventional linear interpolation method to obtain cubic voxel dimensions (i.e. $0.31^{3} \mathrm{~mm}^{3}$ ) as shown in Fig. 1. Square regions of interest (ROIs) were extracted from the vertical cross-sections of Fig. 1 for the 2D multifractal analysis. The ImageJ program developed at the National Institutes of Health and original programs developed by Nakashima and Kamiya (2007) ${ }^{18}$ were used for the digital image processing. 


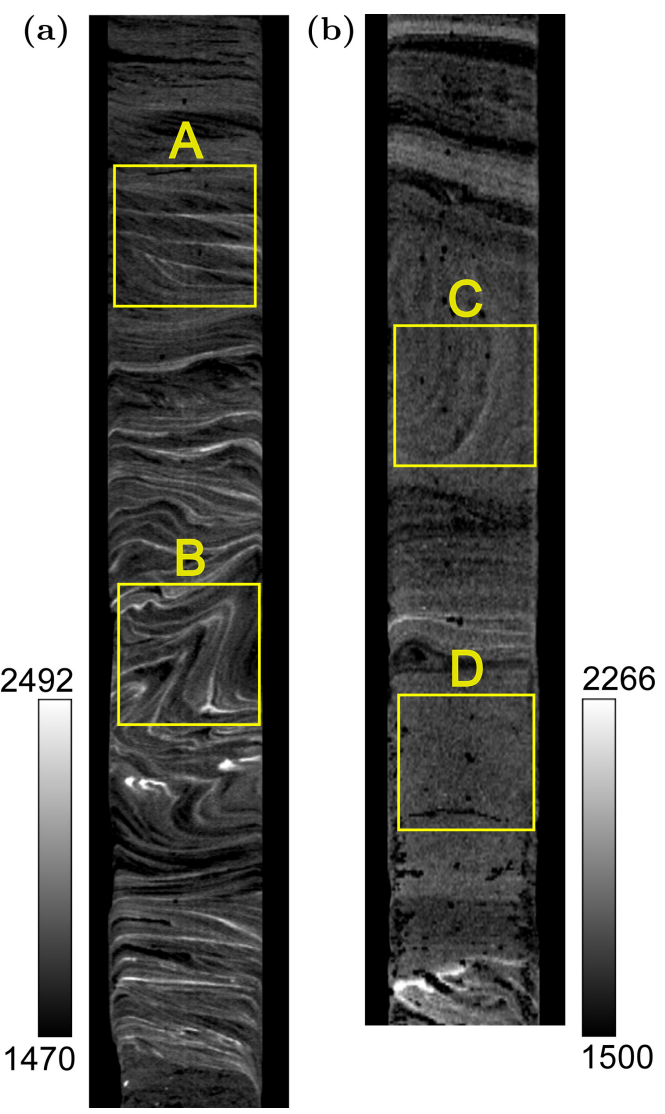

Fig. 1 8-bit X-ray CT images (vertical cross-sections) of boring cores obtained from depths of $(\mathbf{a}) \approx 5 \mathrm{~m}$ and (b) $\approx 10 \mathrm{~m} ! 1534$ The image dimensions are $7.8 \times 42.9 \mathrm{~cm}^{2}$ for (a) and $7.8 \times 39.6 \mathrm{~cm}^{2}$ for (b). The grayscale is in Hounsfield units. Serial-sectioning movies of the cores are available as electronic supplementary files ${ }^{\mathrm{a}}$ (Movie_fig1a.mp4 and Movie_fig1b.mp4). Four ROIs (A to D) for the multifractal analysis are indicated by yellow squares.

Ferro- and para-magnetic minerals were collected from the $\approx 5 \mathrm{~m}$ deep core sample using a $\mathrm{Nd}$ Fe-B magnet. X-ray fluorescence analyses of the magnetically collected minerals revealed that the elemental composition heavier than potassium and $\geq 1$ wt.\% comprised Ca (7 wt.\%), Ti (3 wt.\%), and Fe $(30 \mathrm{wt} . \%)$. The X-ray attenuation coefficient is significantly increased with the atomic number $\frac{17}{17}$; therefore, the main contribution to the $\mathrm{CT}$ image intensity is the amount of iron within the voxel (neither calcium nor titanium). According to powder $\mathrm{X}$-ray diffraction analysis with the reference intensity ratio method, the collected minerals include ferrosilite (20 wt.\%), magnetite (12 wt.\%), hematite ( 1 wt.\%), and amphibole ( $1 \mathrm{wt.} \%)$. Thus, it is reasonable to interpret the obtained CT images as the

a These files can be accessed at http://www.worldscientific. com/doi/suppl/10.1142/S0218348X18500184 spatial distribution of these iron-bearing mineral phases.

After nondestructive acquisition of the CT images shown in Fig. 1, the water-saturated sediments were extracted from the core, specially treated as follows, and imaged by X-ray CT once more. The sediment from the $\approx 10 \mathrm{~m}$ deep core sample (Fig. 1b) containing iron-bearing minerals was placed in a plastic bottle and completely mixed manually with a spoon. X-ray CT images of this homogenized sediment were acquired as a limiting case of mixing (see image E in Fig. 2 2 ). The two sediment samples of Figs. 1 a and 1 b, from which iron-bearing minerals were removed using the $\mathrm{Nd}$ Fe-B magnet, were also imaged by X-ray CT. The

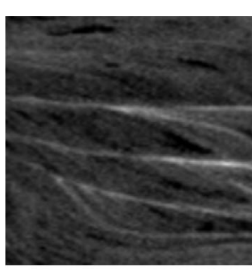

A

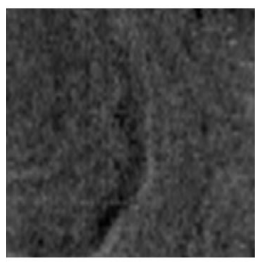

C

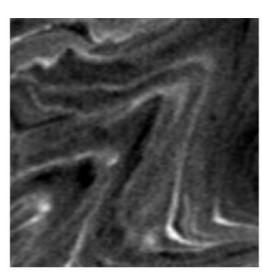

B

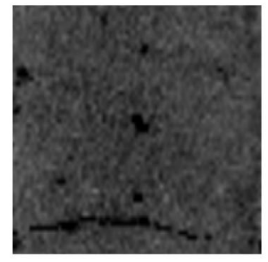

D

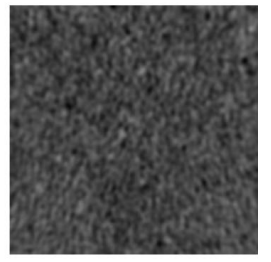

E (a)

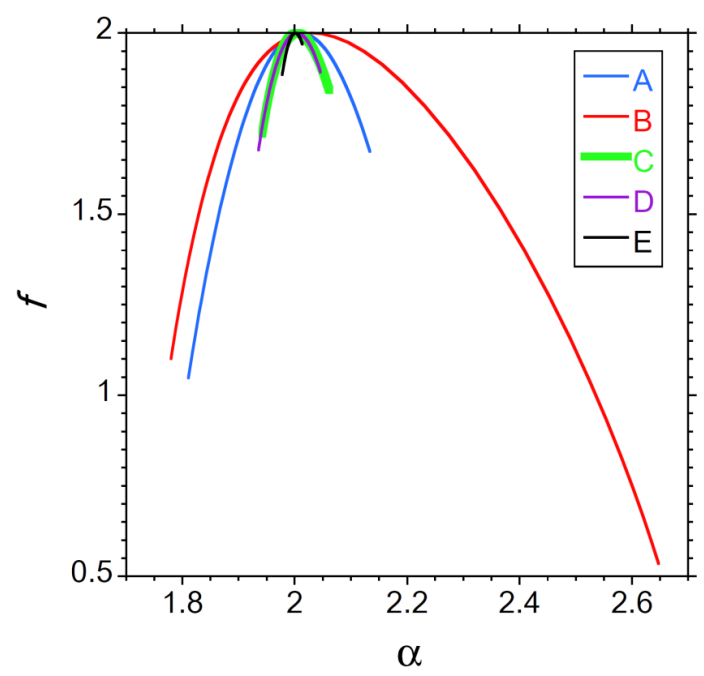

(b)

Fig. 2 Examples of (a) 8-bit 2D CT images (256 2 voxels) and (b) the corresponding $f(\alpha)$ spectra for the $T_{\text {mid }}$ threshold and for the $q$ range of -5 to 10 . The image dimensions of ROISs A to E are $55^{2}, 55^{2}, 58^{2}, 53^{2}$, and $47^{2} \mathrm{~mm}^{2}$, respectively. 


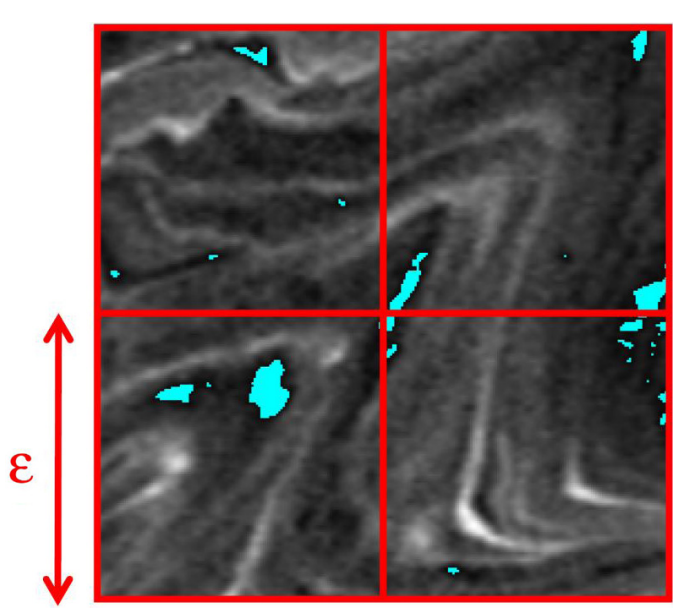

(a)

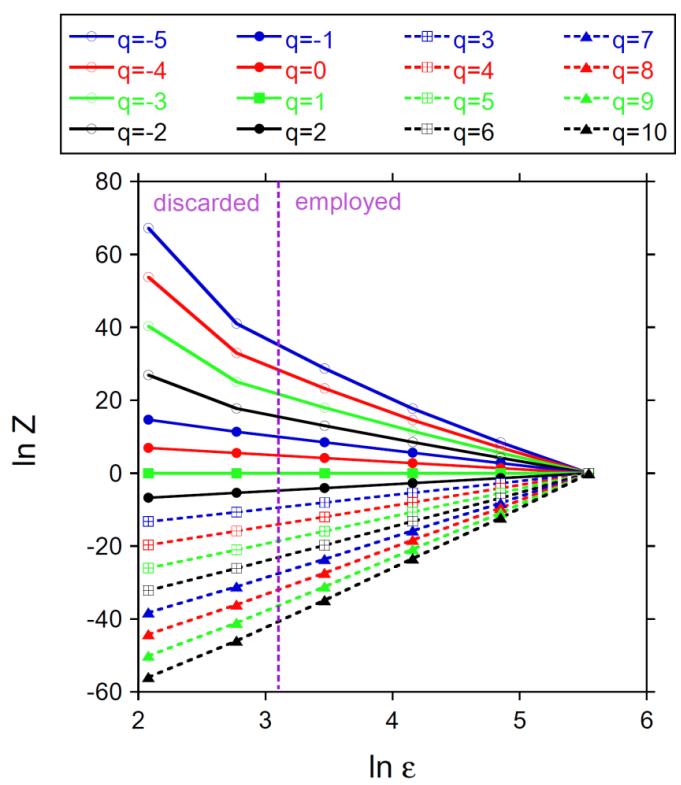

(c)

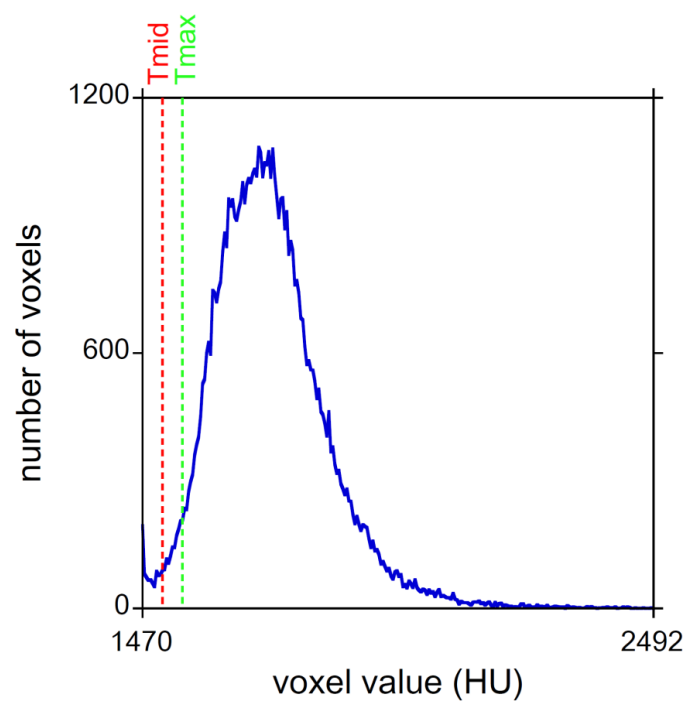

(b)

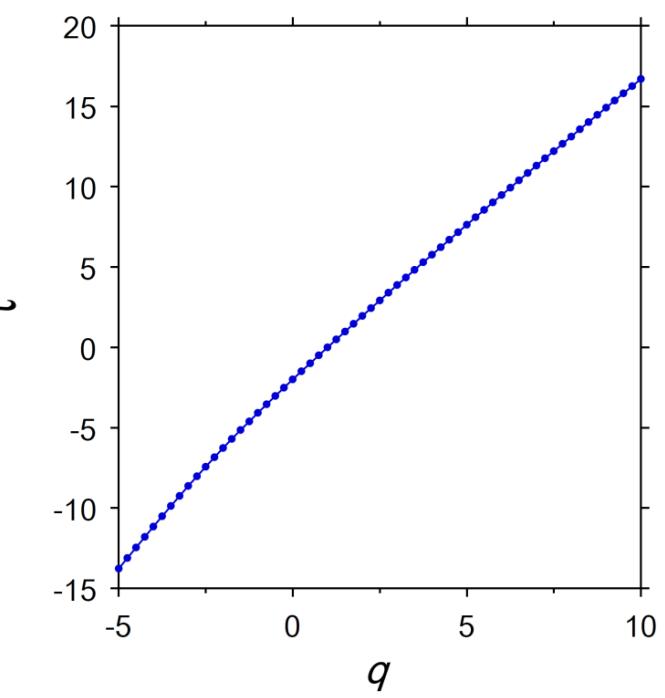

(d)

Fig. 3 Detailed procedure for the multifractal calculation of the 8-bit image B in Fig. [2a. The image is subdivided into small red squares with an edge length of $\varepsilon$. (a) Example for $\varepsilon=128$ voxels. "Iron-free" voxels corresponding to $T_{\text {mid }}$, i.e. voxels with values equal to or less than $1520 \mathrm{HU}$, are colored blue in (a). (b) Histogram of the voxel values in (a). In the present study, three threshold values $\left(T_{\min }=1470 \mathrm{HU}, T_{\operatorname{mid}}=1520 \mathrm{HU}\right.$, and $\left.T_{\max }=1570 \mathrm{HU}\right)$ are applied to the $f(\alpha)$ calculation for image $\mathrm{B}$, and the positions for $T_{\operatorname{mid}}$ and $T_{\max }$ are indicated by vertical dotted lines in (b). For simplicity, however, $T_{\text {mid }}$ of $1520 \mathrm{HU}$ is used for $(\mathbf{c})$ to $(\mathrm{g})$. The iron concentration of each voxel is proportional to the difference of the voxel value and the threshold. The iron amount within each red square in (a), $P i(\varepsilon)$, can thus be calculated by summing the difference, where $i$ is the number assigned to each square in (a). $P i(\varepsilon)$ is normalized so that $\Sigma P i(\varepsilon)=1$, where the summation is performed with respect to all squares for a fixed $\varepsilon$. The moment, $Z(\varepsilon)=\Sigma P i(\varepsilon)^{q}$, is calculated for non-zero $\operatorname{Pi}(\varepsilon)$, where $q$ is a systematically tuned exponent. An example for $q=-5$ to 10 is shown in (c). The linearity in the $\log -\log$ plot breaks down for $\varepsilon \leq 2^{3}$ voxels for some $q$ values in (c). Although not shown, the linearity also breaks down for $\varepsilon \leq 2^{4}$ voxels for the synthetic images in Fig. ESM1. Thus, data points for $\varepsilon \leq 2^{4}$ voxels are discarded in the present study, and those for $\varepsilon=2^{5}$ to $2^{8}$ voxels are employed to calculate the $\tau$ value as a slope of the $\log -\log$ plot (i.e. assuming $Z \sim \varepsilon^{\tau}$ ). The obtained $\tau$ is plotted as a function of $q$ in (d) for a $q$ increment of 0.25 . The $q$-dependent generalized dimension, $D q$, is calculated by $D q=\tau /(q-1)$ for $q \neq 1$, whereas $D_{1}$ is calculated as the slope of the $\Sigma P i(\varepsilon) \ln P i(\varepsilon)$ versus $\ln \varepsilon$ plot. An example for the $D_{1}$ calculation is shown in (e) with a linear regression line (dotted). All $D q$ data points, including $D_{1}$, are plotted in (f) for $q=-5$ to 10 with a $q$ increment of 0.25 . The Lipschitz-Hölder exponent, $\alpha$ and the multifractal spectrum, $f(\alpha)$, are calculated by $\alpha=d \tau / d q$ and $f=q \alpha-\tau$, respectively, as shown in (g). To quantify the degree of opening of $f(\alpha)$ near the maximum, Eq. (1) is fitted to $f(\alpha)$ using the nine data points of $-1 \leq q \leq 1$. 


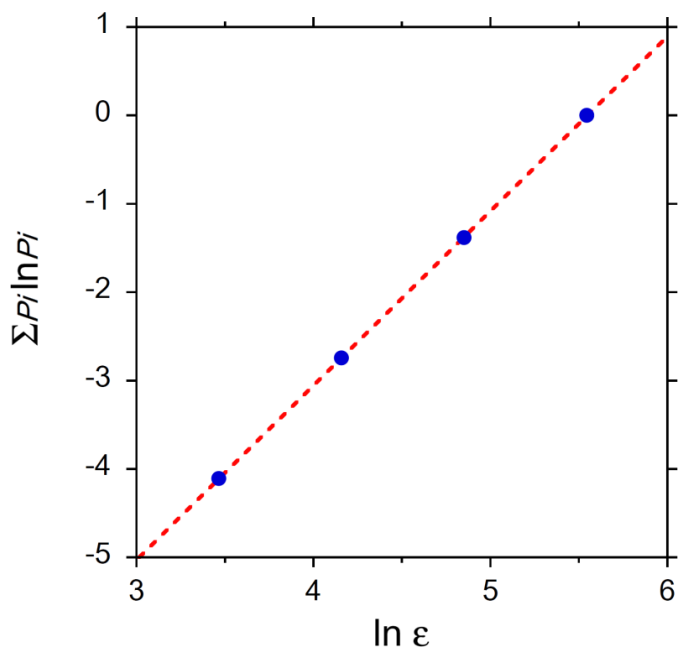

(e)

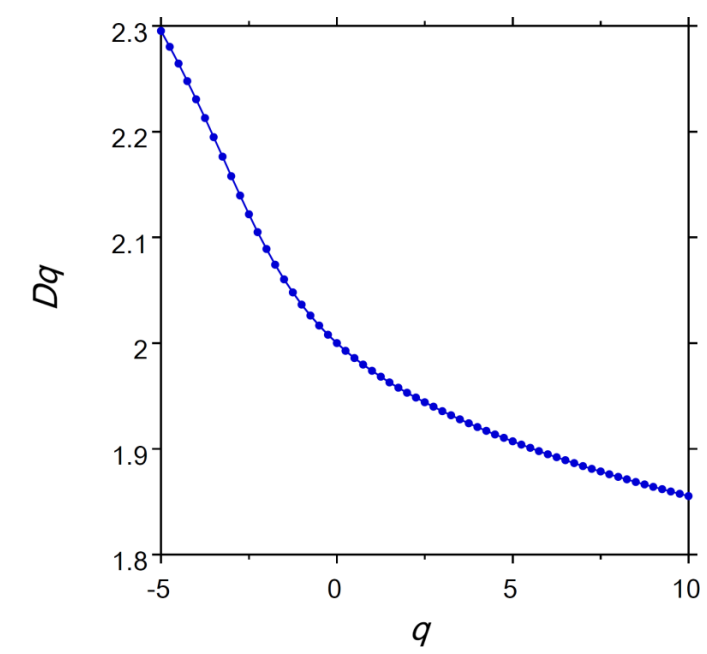

(f)

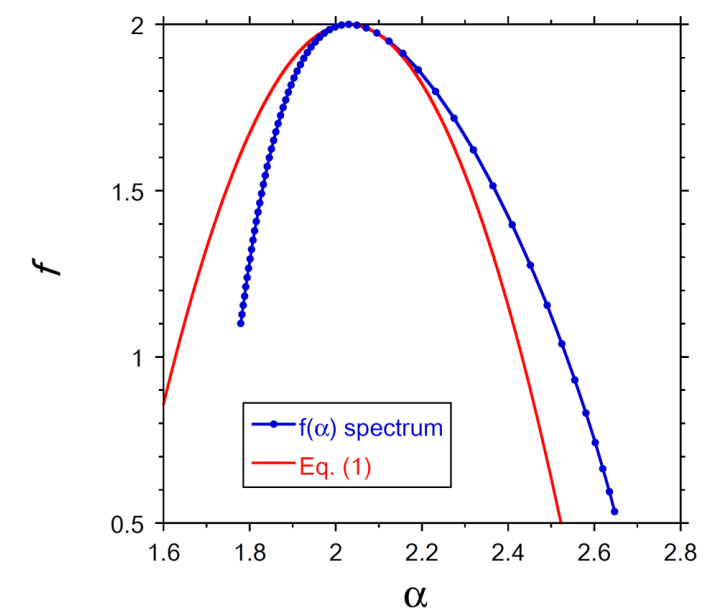

(g)

Fig. 3 (continued)

purpose is to obtain "iron-free" CT images that are essential to convert the raw CT images into ironconcentration images, which is described in Sec. 2.2.

\subsection{Multifractal Analyses of CT Images}

For the 2D multifractal analysis of CT images (Fig. 2), the method of moments $19 \sqrt[28 \mid 4146]{46}$ was employed, which is a conventional scheme (Fig. 3). The dependence of moment, $Z(\varepsilon)$, on the square edge length, $\varepsilon$ is critical in the method. To ensure the linearity in the $\ln Z(\varepsilon)$ versus $\ln \varepsilon$ plot (not only Fig. 3r but all data including synthetic images), the square edge length, $\varepsilon$ was assumed to be $2^{5}$ to $2^{8}$ voxels, and in most cases the exponent, $q$, used for the calculation of the moment was in the range from
-5 to 10 . The detailed procedure to obtain the multifractal spectrum, $f(\alpha)$, where $\alpha$ is the LipschitzHölder exponent, is depicted in Fig. 3.

Five square ROIs, A to E, which display different SSDSs arrangements, were processed in the present study. Example images from the five ROIs are shown in Fig. 2h. ROIs A to D are from the core CT images of Fig. 1, while ROI E is from a CT image for the manually homogenized sediment containing iron-bearing minerals, sampled from Fig. 1 $b$. The dimensions of each image should ideally be powers of two to cover the entire image without residuals, whereby small squares with an edge length of $\varepsilon$ are correctly employed (Fig. 3 3 ). However, for example, the original image dimensions of ROIs $\mathrm{A}$ and $\mathrm{E}$ are $176^{2}$ and $150^{2}$ voxels, respectively; therefore, they were slightly expanded 
to $256^{2}$ voxels by image processing (bilinear interpolation) before the multifractal analysis. As shown in Movie_fig1a.mp4 and Movie_fig1b.mp4, the CT image data set is originally three-dimensional (3D). Thus, 20 2D slice images parallel to each other (slice distance, $0.9 \mathrm{~mm}$ ) were extracted from the $3 \mathrm{D}$ data set corresponding to ROIs A to D, while $102 \mathrm{D}$ slices parallel to each other (slice distance, $3.0 \mathrm{~mm}$ ) were extracted from the 3D data set of ROI E. The multifractal analysis was applied to a total of $902 \mathrm{D}$ images of $256^{2}$ voxels to evaluate the effects of the 3D heterogeneity.

The voxel values of the original $\mathrm{CT}$ images are dimensionless integers in Hounsfield units (HU), which is the normalized linear attenuation coefficient of the X-rays. The voxel values were converted into iron concentration as follows. Iron-bearing minerals were removed from the two sediment samples of Figs. 17a and 10 using the Nd-Fe-B magnet. The "iron-free" samples were placed into plastic graduated cylinders, homogenized completely by shaking, and imaged by X-ray CT under the same imaging conditions as Fig. 11. As for the "iron-free" sample collected from the depth interval of Fig. 19 (depth $\approx 5 \mathrm{~m})$, the arithmetic average and standard deviation of the obtained CT images were $1520 \mathrm{HU}$ and $50 \mathrm{HU}$, respectively (the number of voxels analyzed was 16,000). Thus, three values were employed for the threshold, $T_{\text {min }}, T_{\text {mid }}$ and $T_{\max }$, as the voxel values of sediments devoid of iron-rich mineral phases for ROIs $\mathrm{A}$ and $\mathrm{B}$; $T_{\min }=1520-50=1470 \mathrm{HU}, T_{\text {mid }}=1520 \mathrm{HU}$, and $T_{\max }=1520+50=1570 \mathrm{HU}$ (see Fig. 3b). As for the homogenized core sediment sample without iron-bearing minerals collected from the different depth interval (depth $\approx 10 \mathrm{~m}$, Fig. 1 b), the arithmetic average and standard deviation were $1540 \mathrm{HU}$ and $40 \mathrm{HU}$, respectively. Thus, for ROIs $\mathrm{C}$ and $\mathrm{E}$, $T_{\min }=1540-40=1500 \mathrm{HU}, T_{\text {mid }}=1540 \mathrm{HU}$, and $T_{\max }=1540+40=1580 \mathrm{HU}$. These thresholds were subtracted from the original voxel values before the multifractal processing to ensure that spatial distribution of the iron concentration was analyzed.

A parabola, Eq. (1), is useful to quantify the multifractal diversity or the degree of opening of the $f(\alpha)$ spectrum near the maximum:

$$
f(\alpha)=-\beta\left(\alpha-\alpha_{0}\right)^{2}+f_{0},
$$

where $\beta$ is a constant related to the spectral diversity, and $\alpha_{0}$ and $f_{0}$ are $\alpha$ and $f$ values for $q=0$, respectively[29] The $f(\alpha)$ spectrum is diverse and contains many $\alpha$ components if $\beta$ is small; the $\beta$ value is large for almost monofractal images. In the present study, Eq. (11) was fitted to $f(\alpha)$ for the nine data points of $-1 \leq q \leq 1$ ( $q$ increment of $0.25)$ to obtain $\beta$ for various images and thresholds (e.g. Fig. 3ig).

\subsection{Mixing Simulations by the Egg-Beater Flow Model}

2D mixing simulations using the obtained digital CT images of sediments were performed to examine the effects of the degree of deformation/mixing on the multifractal diversity, $\beta$. The egg-beater flow mode ${ }^{[14 \mid 16}$ with a periodic boundary condition (Fig. ESM1, electronic supplementary material) was employed as the simulation algorithm. The dominant deformation/mixing mechanism of fluidized strata is assumed as the Rayleigh-Taylor instability triggered by the mechanical vibration of earthquakes.1 13 The main velocity field of the Rayleigh-Taylor flow is the upward flow of buoyant fluidized strata followed by lateral flow to compensate the mass transported upwards. $\frac{30}{30}$ This velocity field is well mimicked by the egg-beater flow model (Fig. ESM1a) ${ }^{\mathrm{b}}$, which suggests that the model could reproduce the seismically induced SSDSs recorded in the cores. Before application to the CT images of real cores, synthetic images with different undisturbed banded structures were deformed by the egg-beater flow model (Fig. ESM1) to examine the performance, particularly the effect of the initial banded structure on the $\beta$ value (Fig. ESM2).

\section{RESULTS}

Figure 2a shows examples of 2D CT images extracted from ROIs (see Fig. 1 for A to D) of the 3D image data set, in which various degrees of SSDSs were successfully recorded. In terms of sedimentary geology, ROI A is an almost undisturbed strata showing a cross-bedding structure with iron-rich minerals as bright voxels. ROI B depicts a characteristic wavy flow pattern 16131 similar to Sumi-Nagashi (i.e. paper marbling) ${ }^{29132}$ or "frozen" turbulence 33 The wavy pattern suggests that the observed deformation of the soft and watersaturated sediments is conceivably related to vibration triggered by earthquakes. A similar flow pattern can be observed in ROI $\mathrm{C}$, although rather

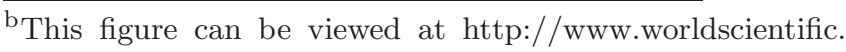
com/doi/suppl/10.1142/S0218348X18500184
} 
obscured, which implies that the region is severely mixed compared with ROI B. The original sedimentary structure is difficult to observe in ROI D, suggesting that the region is almost completely mixed. Several black spots in ROI D (Fig. 2a, and also see the blue spots in Fig. 4 a) are probably air- or waterfilled voids that are undesirably produced due to the specifically employed core drilling method with air bubbles. Vibration cone penetration tests revealed that a depth interval of $\approx 10 \mathrm{~m}$ is more sensitive to mechanical vibrations than that of $\approx 5 \mathrm{~m}$ and tends to be fluidized more easily ${ }^{34}$ This is consistent with the core observation of ROIs $\mathrm{C}$ and $\mathrm{D}$, which are much more deformed than ROIs A and B. There is no evident structure in ROI E image because it was a carefully prepared sediment sample that was mixed and homogenized manually. Thus, the relative intensity of deformation recorded in the five ROIs could be qualitatively ordered as $\mathrm{A}<\mathrm{B}<\mathrm{C}$ $<\mathrm{D}<\mathrm{E}$, which is examined carefully in Sec. 4

The results of the multifractal analysis of the five images in Fig. 2a are shown in Fig. 2b as $f(\alpha)$ spectra. The shape of the $f(\alpha)$ spectrum is evidently dependent on the degree of deformation of the ROIs, and will be discussed in terms of the $\beta$ value in the next section. The $f(\alpha)$ spectrum for the apparently undisturbed image, A of Fig. 2a a, where no deformed structure is evident, is multifractal. The following two interpretations are possible for the multifractality of the apparently undisturbed sediment sample. (i) ROI A was subjected to earthquake vibration, as was the neighboring ROI B,
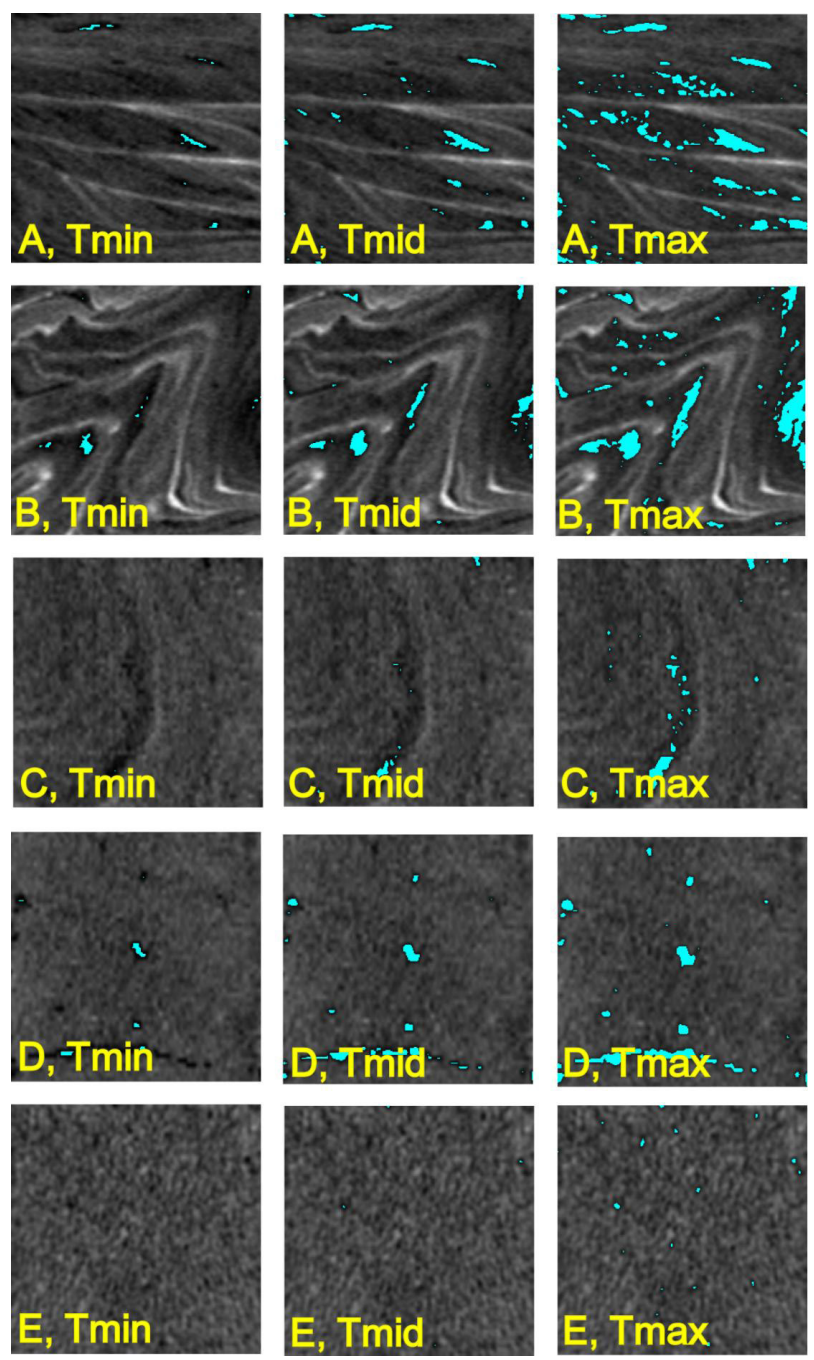

(a)

Fig. 4 Effects of the threshold on the $f(\alpha)$ spectra. (a) Images of Fig. 2 a for various threshold values $\left(T_{\text {min }}, T_{\text {mid }}\right.$, and $\left.T_{\max }\right)$. "Iron-free" voxels with voxel values equal to or less than each threshold are colored blue. (b) Corresponding $f(\alpha)$ spectra. The $q$ range used for the $f(\alpha)$ calculation is -5 to 10 , but is only -3 to 10 for the case of ROI B, $T_{\max }$. 

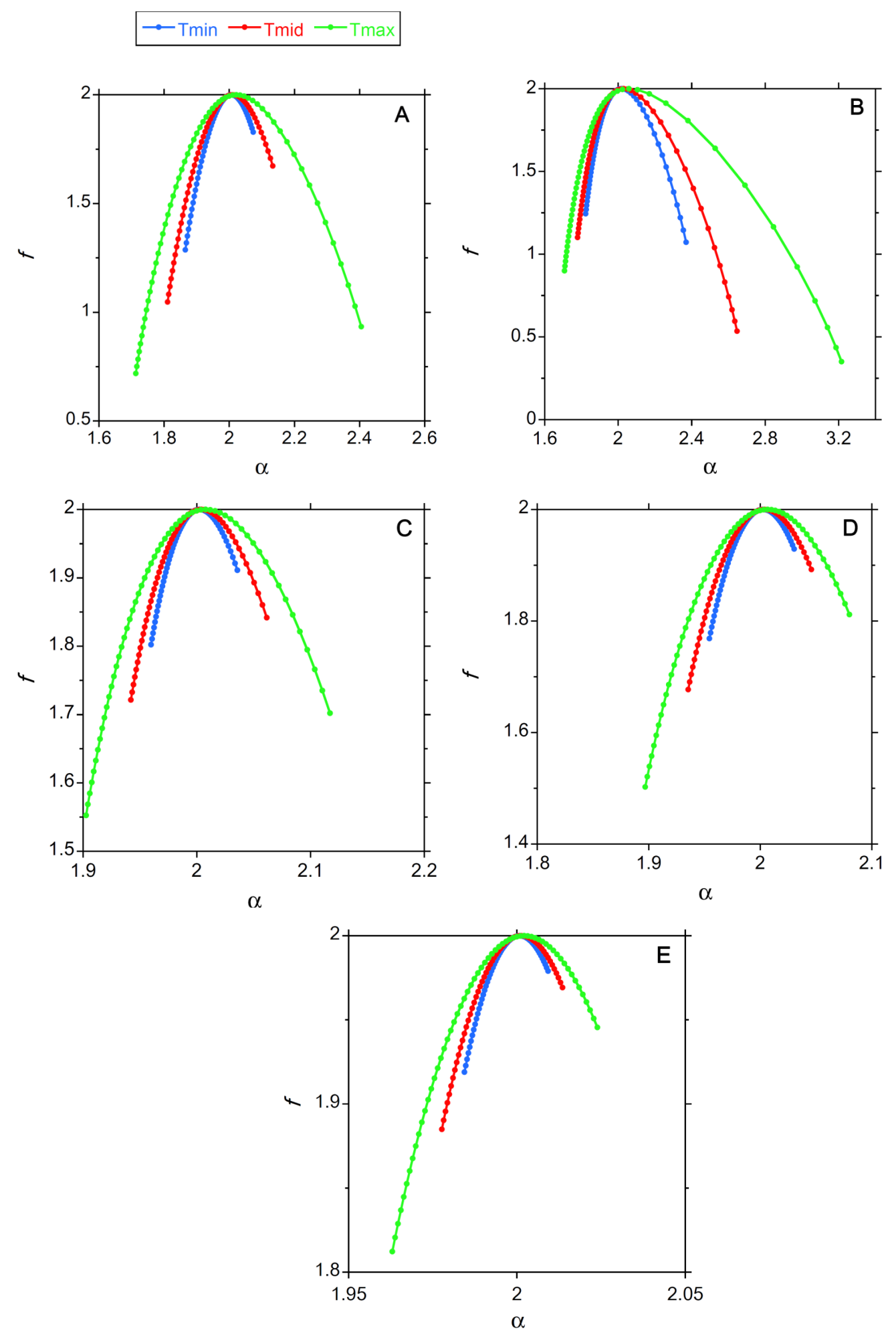

(b)

Fig. 4 (Continued)

and a small degree of fluidization and deformation occurred to yield the observed multifractal spectrum. However, the degree of fluidization was too small to be recognized as deformed wavy structures by the naked eye. (ii) Some naturally deposited sediments have original multifractality even if no earth-

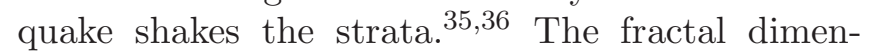
sion of the support, $f_{0}$, is $\approx 2$ for the five images 
(Fig. 2b). This is because the regions free of ironrich mineral phases are too small (see the blue voxels in Fig. 4a) to reduce the $f_{0}$ value in the range of $2^{5}<\varepsilon<2^{8}$ voxels, which allows the approximation that the iron-bearing mineral grains are scattered almost two-dimensionally.

The effects of the three threshold values $\left(T_{\min }\right.$, $T_{\text {mid }}$, and $T_{\max }$ ) and of the $3 \mathrm{D}$ heterogeneity (i.e.
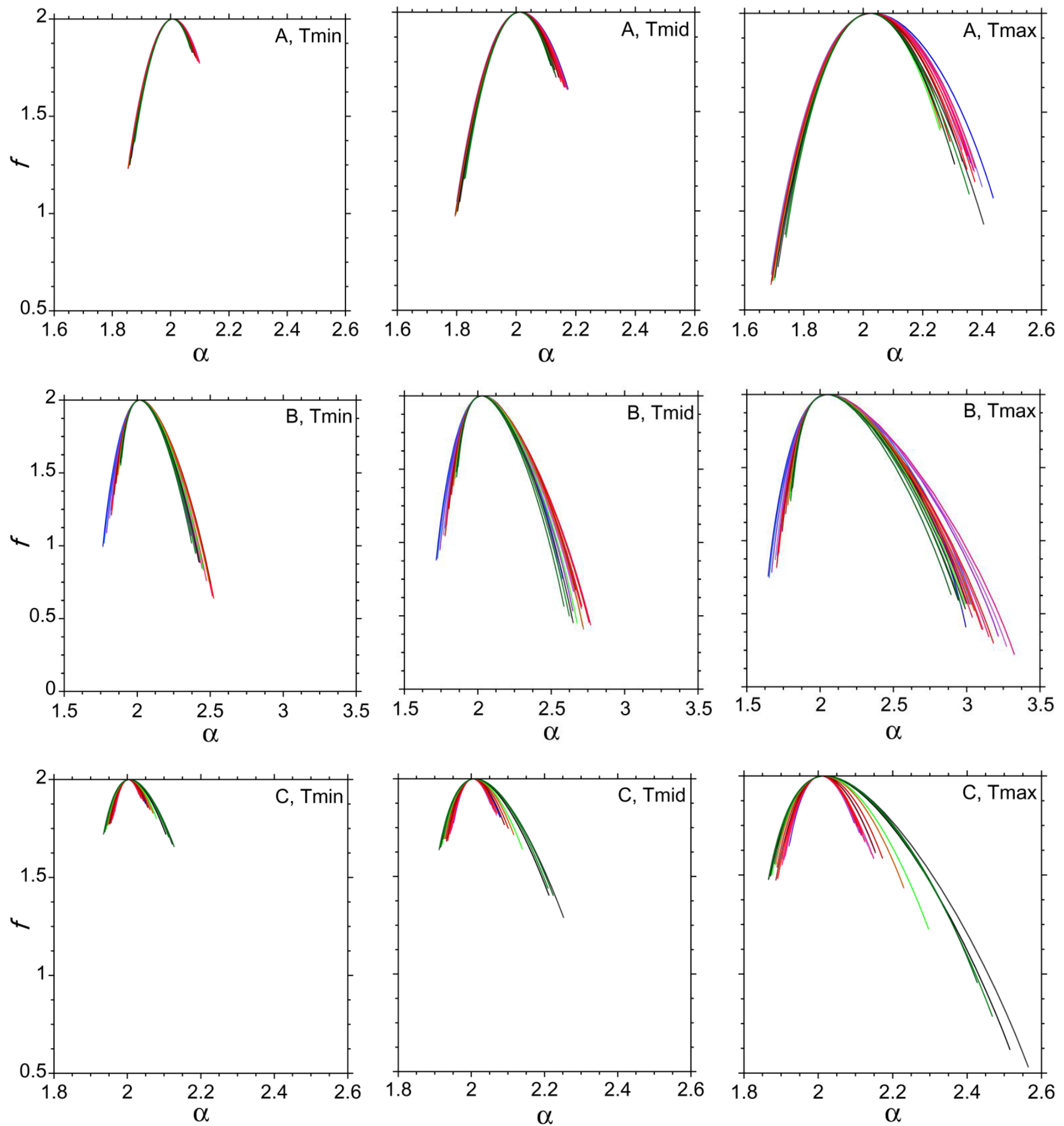

Fig. $5 f(\alpha)$ spectra with different colors for various images. Twenty 2D images extracted from the 3D data set of Fig. 11 were analyzed for ROIs A to D; ten images were extracted for ROI E. Statistics (average and standard deviation) for $\beta$ values related to these 20 or 10 spectra are shown in Fig. 6] The $q$ range used for the $f(\alpha)$ calculation is -5 to 10 . However, to secure the linearity of the $\ln Z-\ln \varepsilon$ plot (e.g. Fig. 3r), the $q$ range is narrowed to -4 to 10 for the eight images of the twenty B $T_{\text {mid }}$ images, and to -3 to 10 for the 19 images of the $20 \mathrm{~B} T_{\max }$ images. 

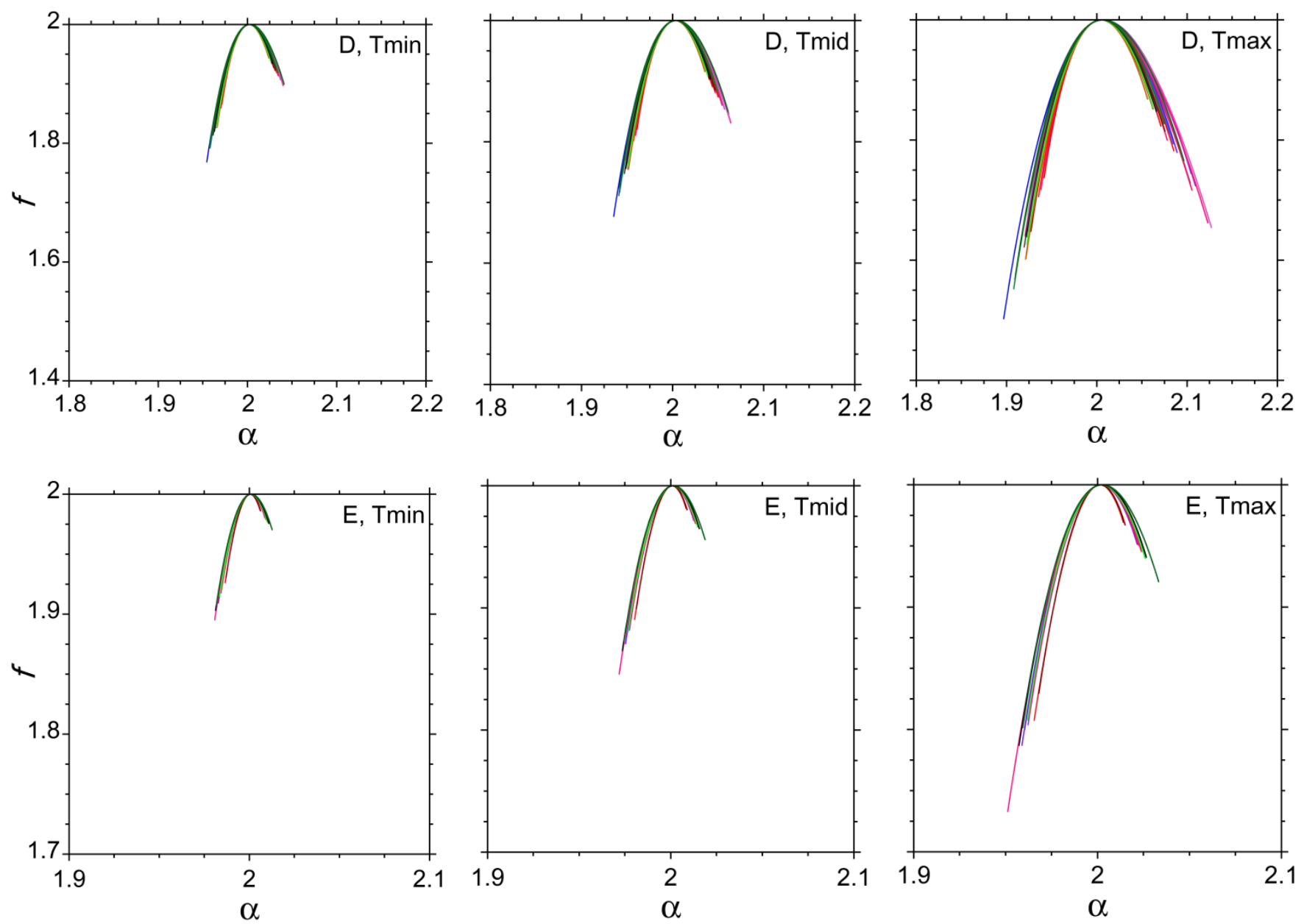

Fig. 5 (Continued)

difference between 2D slices chosen from the same ROI) on the shape of the $f(\alpha)$ spectra are shown in Figs. 4 and 5, respectively. The degree of opening of the $f(\alpha)$ spectra near the maximum increases with the threshold. The arithmetic averages of the $\beta$ values obtained by fitting the parabola, Eq. (1), to the $f(\alpha)$ spectra are summarized in Fig. 6 with the standard deviation presented as an error bar. The $\beta$ value for the completely mixed sediment image of ROI E is not infinite but finite in Fig. 6] and the corresponding $f(\alpha)$ spectrum does not exactly converge on a single point in Fig. 5. The following two are possible reasons for the finiteness of the $\beta$ value. (i) ROI E image analyzed is not completely random but somewhat spatially correlated. Undesirable CT-specific artifacts $37 / 38$ (e.g. beam hardening, ring artifact, or partial volume effects) and the incomplete mixing operation using a spoon could be responsible for the spatial correlation. (ii) Numerically the finite size effect of the voxels could prevent the $f(\alpha)$ spectrum from converging on a single point. ${ }^{22}$

The egg-beater flow model applied to images of ROIs $\mathrm{A}$ and $\mathrm{B}$ of Fig. $2 \mathrm{l}$ for $T_{\text {mid }}$ are shown in Figs. 7 and 8 , respectively. The generated wavy patterns at $t=1$ to 6 in Fig. 7 h are qualitatively similar to images $\mathrm{B}$ and $\mathrm{C}$ in Fig. 2a ; the almost homogeneous pattern at $t=14$ is also similar to image D in Fig. 2a, which suggest that the eggbeater flow model employed could reasonably reproduce the wavy and homogeneous patterns recorded in the core CT images. The degree of the homogeneity or mixing, $\beta$, increases as a function of time, $t$, in Figs. $7 \mathrm{k}$ and $8 \mathrm{k}$. This temporal behavior is an important outcome of the egg-beater flow simulations, and will be discussed in Sec. 4 .

Figure 9 summarizes the temporal change of the $\beta$ values for the egg-beater flow simulations applied to the four images of ROIs A to D for the three thresholds. The trajectories for ROIs C 


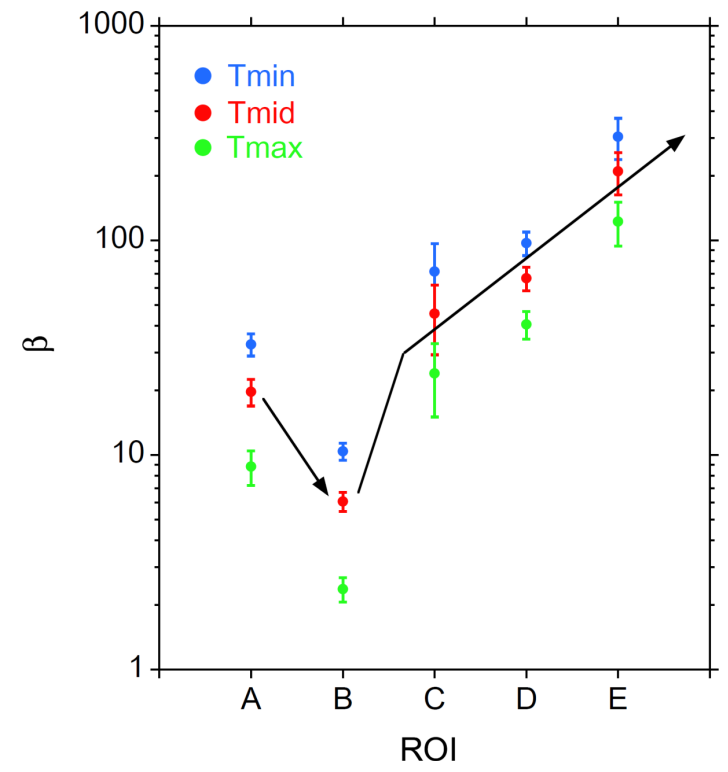

Fig. 6 Dependence of the $\beta$ parameter on the deformation intensity of SSDSs with the order of $\mathrm{A}<\mathrm{B}<\mathrm{C}<\mathrm{D}<\mathrm{E}$, and on the three threshold values $\left(T_{\min }, T_{\operatorname{mid}}\right.$, and $\left.T_{\max }\right)$. The average value obtained by fitting Eq. (1) to the $f(\alpha)$ spectra in Fig. 5 is plotted. The standard deviation for the fitted $\beta$ values is indicated as an error bar. The tentative trend of the $\beta$ value is shown by the solid arrows.

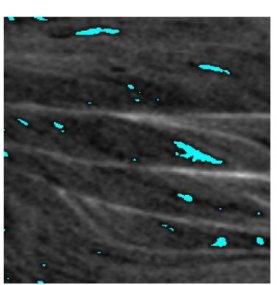

$t=0$

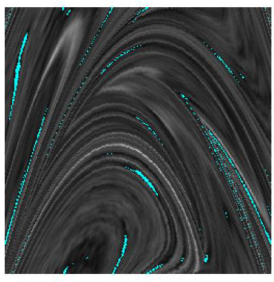

$t=3$

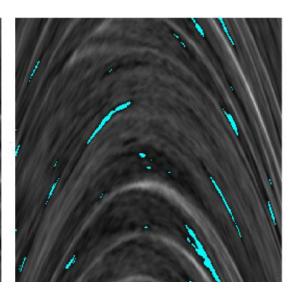

$t=1$

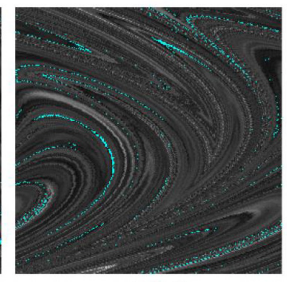

$t=6$

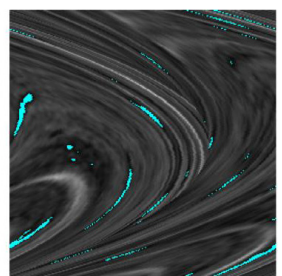

$t=2$

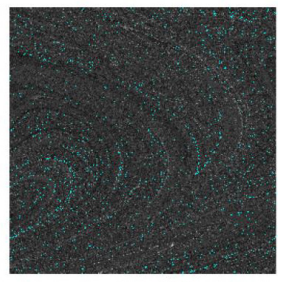

$t=14$ (a)

Fig. 7 Mixing simulations by application of the egg-beater flow model to image A of Fig. $2 \mathrm{a}$ for a $T_{\text {mid }}$ of $1520 \mathrm{HU}$. (a) Snapshots at several mixing time steps, $t$, where "ironfree" voxels with voxel values equal to or less than $1520 \mathrm{HU}$ are colored blue, and (b) corresponding $f(\alpha)$ spectra. The $q$ range used for the $f(\alpha)$ calculation is -5 to 10 with a $q$ increment of 0.25 . (c) Measure of the spectral diversity, $\beta$ obtained by Eq. (II) as a function of $t$. Results for the two synthetic images in Fig. ESM1 are also superimposed on (c).

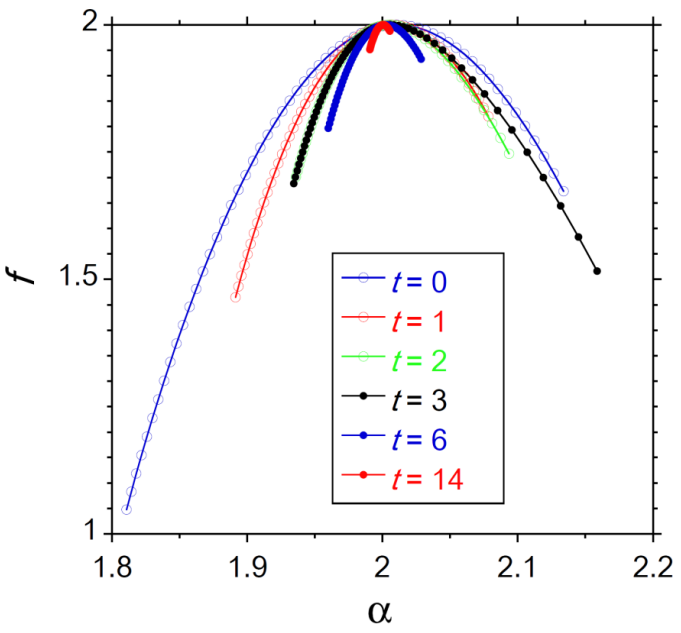

(b)

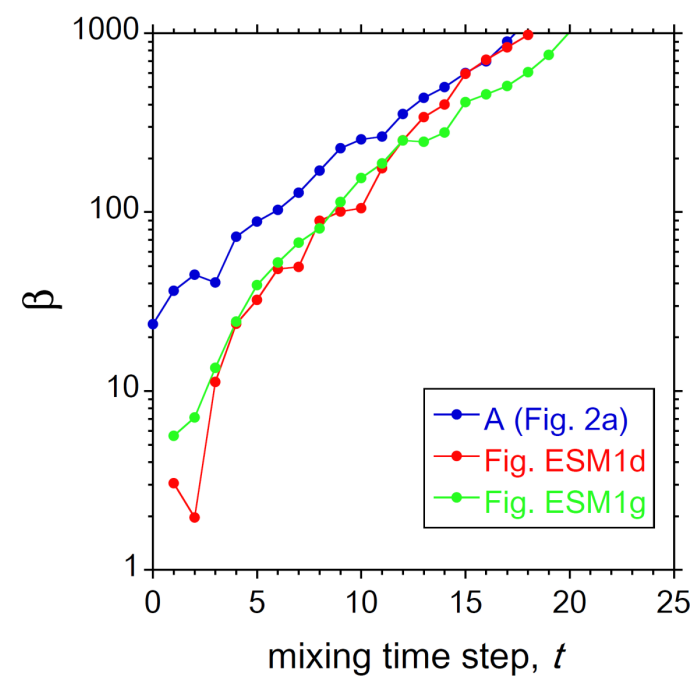

(c)

Fig. 7 (Continued)

and D are tentatively shifted by four time steps to overlap those for ROI A. Simulation results with $\beta$ values larger than the horizontal dotted lines in Fig. 9 are probably of no use when discussing the multifractality of CT images of real cores, because the dotted lines are for the most homogenized images obtained by CT imaging apparatus with the inevitable artifacts.

\section{DISCUSSION}

The present study revealed the multifractality of seismically induced SSDSs of strata. The egg-beater flow model with a synthetic undisturbed image as an initial image depicts important aspects of the relationship between the multifractality and the degree of SSDSs. Figures ESM1b and ESM1e show 


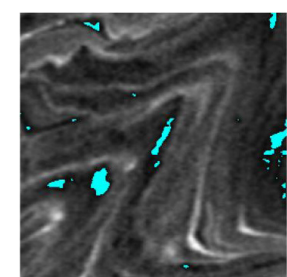

$t=0$

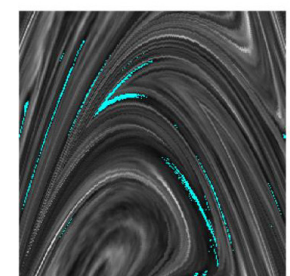

$t=3$

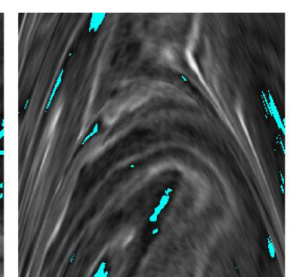

$t=1$

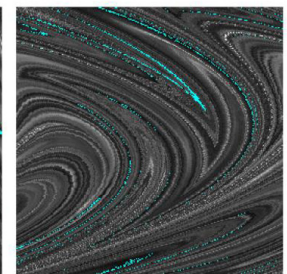

$t=6$

(a)

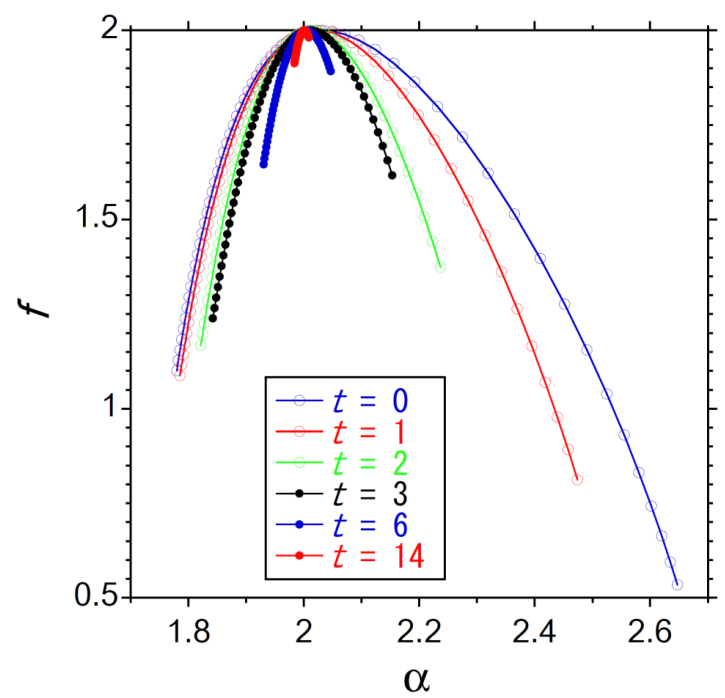

(b)

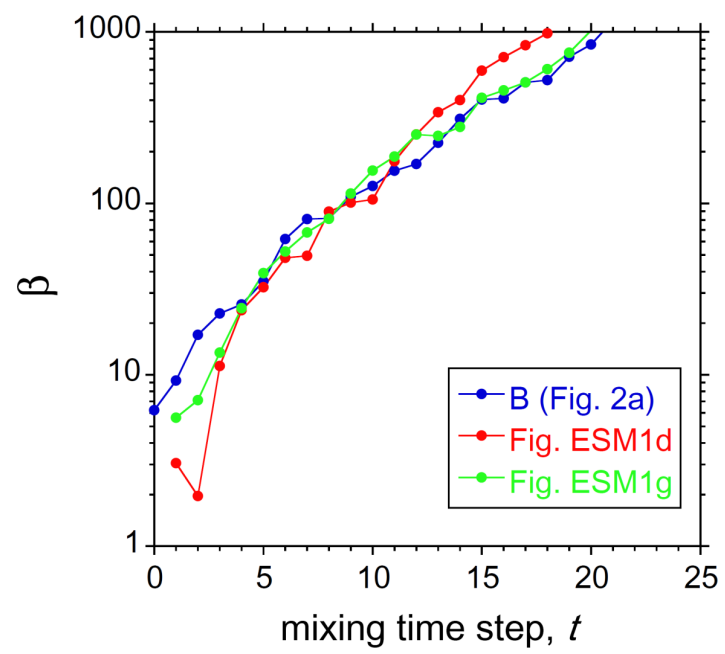

(c)

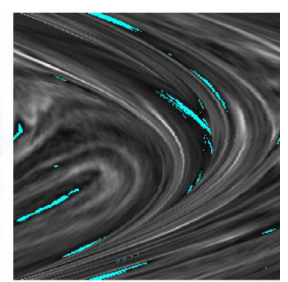

$t=2$

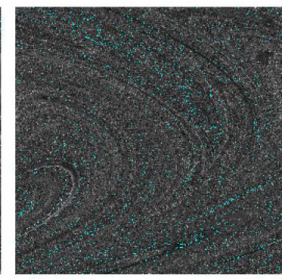

$t=14$

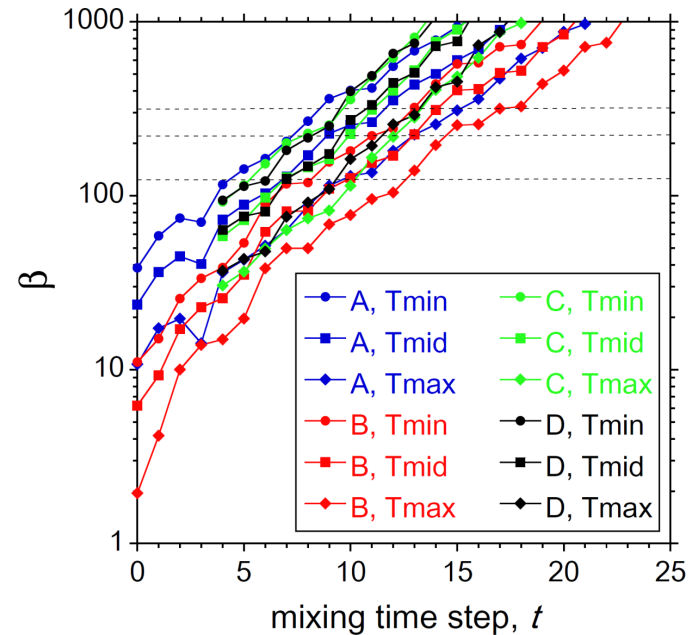

Fig. 9 The diversity of $f(\alpha)$ spectra, $\beta$ as a function of the integer mixing time, $t$, for four images (A to D in Fig. 2a) and three thresholds $\left(T_{\min }, T_{\operatorname{mid}}\right.$, and $\left.T_{\max }\right)$. The integer time is tentatively shifted by 4 for $\mathrm{C}$ and $\mathrm{D}$ to overlap the trajectories of $\mathrm{A}$. The averages of the $\beta$ values with respect to image $\mathrm{E}$ in Fig. 6 for the three thresholds are shown by dotted lines.

that the initial image of the undisturbed strata at $t=0$ changes into the macroscopically nearhomogeneous image at $t=18$ via wavy structures at $t=1$ to 11. Systematic simulations (Fig. ESM2) revealed the dependence of the $\beta$ value on the iron concentration contrast (i.e. case (a) versus case (b)) and on the layer thickness (i.e. $L$ ). Six of the ten trajectories in Fig. ESM2 show drops of the $\beta$ value at $t=2$ or 3 followed by the almost monotonic increase, while four of the ten trajectories show no drops in the early stage (i.e. $2 \leq t \leq 3$ ) of the mixing process. Although the data point of $\beta$ for $t=0$ was not plotted in Figs. ESM1 and ESM2 due to the numerical difficulty, theoretically it should be infinite and the corresponding $f(\alpha)$ spectrum should be reduced to a single point. Thus, the data point at $t=1$ should yield a minimum for the four trajectories mentioned above. In conclusion, the simulation results using synthetic initial images (Figs. ESM1 and ESM2) enable the deformation/mixing process of strata to be understood in terms of the timedependent fractality as follows. The $\beta$ value drops drastically from infinite at $t=0$ to finite in the very early stage (i.e. $1 \leq t \leq 3$ ) of the mixing process. The timing and degree of the drop depend on the initial image. The $\beta$ value then increases almost monotonically, and the corresponding $f(\alpha)$ spectrum tends to converge on a single point (i.e. $f=\alpha=2$ ) as mixing proceeds.

Fig. 8 Same as Fig. 7 but for image B of Fig. 2 a. 
Thus, the multifractality observed in real core images can be interpreted as follows. The core CT images (Figs. 1 and 2a) obtained show systematic changes in the degree of deformation of SSDSs according to the order of $\mathrm{A}<\mathrm{B}<\mathrm{C}<\mathrm{D}<\mathrm{E}$. This is a geological consequence of almost undisturbed strata (image A of Fig. 2a) being deformed and mixed by seismically induced fluidization, and eventually the strata become almost completely homogenized (images D and E of Fig. 2a) via the characteristic wavy structure (images $\mathrm{B}$ and $\mathrm{C}$ of Fig. $2 \mathrm{a}$ ). The order of the mixing time step, $t$, can thus be qualitatively taken as $\mathrm{A} \rightarrow \mathrm{B} \rightarrow \mathrm{C} \rightarrow \mathrm{D}$ $\rightarrow$ E, and Fig. 2a can be interpreted as serial snapshots of the deformation process of a single sample. According to the extensive multifractal analyses presented in Figs. 4 and 5 , the obtained $f(\alpha)$ spectra show evidence for the dependence on the degree of deformation of the SSDSs. Although fluctuation due to the choice of the three thresholds and to the 3D core heterogeneity is observed in Fig. 66 the corresponding parameter, $\beta$ shows the drop for the image $\mathrm{B}$ followed by the monotonic increase (see the black arrow in Fig. 6). The drop probably occurred during the change from ROI A to $\mathrm{B}$ due to enhancement of the multifractality, which should theoretically occur at the very early stage of mixing (Fig. ESM2). The temporal behavior of the $\beta$ value ( $\mathrm{A}$ to $\mathrm{E}$ in Fig. 6 ) including the monotonic increase after the drop is almost the same as that observed with the simulations using the synthetic images (Fig. ESM2) and the literature 29139 on fluid mixing, which suggests that the observed dependence of the multifractality (Figs. 2 and 6) on the degree of deformation of SSDSs is the outcome of the mixing of fluidized strata.

Results for application of the egg-beater flow model to the real core CT image in Fig. 7 support this interpretation. The original undisturbed image at $t=0$ in Fig. $7 \mathrm{a}$ changes into almost homogeneous images via wavy structures with the increase in the mixing time step, $t$. The corresponding $f(\alpha)$ spectra in Fig. $7 \mathrm{~b}$ show the transformation from the multifractal state to the almost monofractal state with an increase of the mixing time. The parameter, $\beta$ in Fig. 7c increases with time $t$ with a small drop at $t=3$. These results are similar to those for the simulations using synthetic images (Figs. ESM1 and ESM2), which also suggests that the dependence of multifractality (Figs. 2]and 6) on the degree of deformation of SSDSs is a result of the mixing of fluidized strata.

Figure 9 summarizes the results for the eggbeater flow model applied to images $\mathrm{A}$ to $\mathrm{D}$ in Fig. 2a. All 12 trajectories show the transformation from the multifractal state with relatively small $\beta$ values to the almost monofractal state with larger $\beta$ values as the mixing time step increases. The results in Fig. 9 enable the approximate estimation of the "distance" between images, in terms of the difference in $\beta$ values as a function of $t$. For example, the distance between (i) the obscure and vague images $\mathrm{C}$ and D in Fig. 2a, and (ii) image A with clear sedimentological laminations seems significant. The trajectories for $\mathrm{C}$ and $\mathrm{D}$ that are tentatively shifted by four time steps mostly overlap those for A (Fig. 9). The dependence on the thresholds $\left(T_{\text {min }}, T_{\text {mid }}\right.$, and $\left.T_{\max }\right)$ is not negligible; therefore, it is difficult to quantify this overlap exactly. However, the overlap obtained by tentative shift allows us to estimate that images $\mathrm{C}$ and $\mathrm{D}$ advance approximately by four time steps in terms of the egg-beater flow model employed.

The present study revealed the dependence of the multifractal spectra on the degree of deformation/mixing triggered by vibration from earthquakes. The degree of deformation of strata is directly linked to the degree of the past seismic activity and susceptibility of the site (e.g. epicentral distance and soil rigidity) ${ }^{[7] 10]}$ Multifractal analysis coupled with X-ray CT and the mixing flow model described here could thus represent a novel method for the quantitative evaluation of cores in terms of seismic risk assessment.

\section{CONCLUSIONS}

The present study revealed the multifractality of the seismically induced SSDSs. The spatial distribution of iron-bearing minerals in the obtained CT images is multifractal for less deformed/mixed strata, and almost monofractal for fully deformed/mixed (i.e. almost homogenized) strata. Simulations of deformation of digital images using the egg-beater flow model successfully reproduced the temporal change of the multifractal spectra into almost monofractal spectra (i.e. almost convergence on a single point) with an increase in deformation/mixing intensity. Multifractal analysis coupled with X-ray CT and mixing simulations is demonstrated as useful for quantitative analysis of the complexity of SSDSs, 
and would therefore represent a novel method applicable to seismic risk assessment.

\section{ACKNOWLEDGMENTS}

Comments by two anonymous reviewers were helpful. Python and Lua programming for the multifractal analysis was performed by S. Kamiya. The X-ray CT scanner installed at the GSJ-Lab, AIST was used. The present study was supported in part by a Kakenhi Grant-in-Aid (No. 23241012) from the Japan Society for the Promotion of Science (JSPS).

\section{REFERENCES}

1. R. J. Nichols, R. S. J. Sparks and C. J. N Wilson, Experimental studies of the fluidization of layered sediments and the formation of fluid escape structures, Sedimentology 41 (1994) 233-253.

2. M. Moretti, P. Alfaro, O. Caselles et al., Modelling seismites with a digital shaking table, Tectonophysics 304 (1999) 369-383.

3. N. Yasuda and I. Sumita, Effect of viscosity on the shaking-induced fluidization in a liquid-immersed granular medium, Phys. Rev. E 93(2) (2016) 022901.

4. N. Rana, F. Bhattacharya, N. Basavaiah et al., Soft sediment deformation structures and their implications for late quaternary seismicity on the south Tibetan detachment system, central Himalaya (Uttarakhand), India, Tectonophysics 592 (2013) $165-174$.

5. A. T. Van Loon and M. Pisarska-Jamroży, Sedimentological evidence of Pleistocene earthquakes in NW Poland induced by glacio-isostatic rebound, Sediment. Geol. 300 (2014) 1-10.

6. M. R. Onorato, L. Perucca, A. Coronato et al., Seismically-induced soft-sediment deformation structures associated with the Magallanes-Fagnano Fault System (Isla Grande de Tierra del Fuego, Argentina, Sediment. Geol. 344 (2016) 135-144.

7. S. F. Obermeier, Use of liquefaction-induced features for paleoseismic analysis - An overview of how seismic liquefaction features can be distinguished from other features and how their regional distribution and properties of source sediment can be used to infer the location and strength of Holocene paleo-earthquakes, Eng. Geol. 44 (1996) $1-76$.

8. G. Owen and M. Moretti, Identifying triggers for liquefaction-induced soft-sediment deformation in sands, Sediment. Geol. 235(3) (2011) 141-147.

9. G. Owen, M. Moretti and P. Alfaro, Recognising triggers for soft-sediment deformation: Current understanding and future directions, Sediment. Geol. 235(3) (2011) 133-140.
10. M. Moretti and A. T. van Loon, Restrictions to the application of 'diagnostic' criteria for recognizing ancient seismites, J. Palaeogeogr. 3(2) (2014) 162173.

11. A. B. Chhabra, C. Meneveau, R. V. Jensen et al., Direct determination of the $f(\alpha)$ singularity spectrum and its application to fully developed turbulence, Phys. Rev. A 40(9) (1989) 5284.

12. J. M. Ottino, Mixing, chaotic advection, and turbulence, Ann. Rev. Fluid Mech. 22(1) (1990) 207-254.

13. K. Sreenivasan, Fractals and multifractals in fluid turbulence, Ann. Rev. Fluid Mech. 23(1) (1991) 539-604.

14. F. J. Muzzio, C. Meneveau, P. D. Swanson et al., Scaling and multifractal properties of mixing in chaotic flows, Phys. Fluids A 4(7) (1992) 1439-1456.

15. Y. Nakashima and J. Komatsubara, Seismically induced soft-sediment deformation structures revealed by X-ray computed tomography of boring cores, Tectonophysics 683 (2016) 138-147.

16. J. M. Ottino, The mixing of fluids, Sci. Am. 260(1) (1989) 56-57.

17. Y. Nakashima, The use of X-ray CT to measure diffusion coefficients of heavy ions in water-saturated porous media, Eng. Geol. 56(1) (2000) 11-17.

18. Y. Nakashima and S. Kamiya, Mathematica programs for the analysis of three-dimensional pore connectivity and anisotropic tortuosity of porous rocks using X-ray computed tomography image data, J. Nucl. Sci. Technol. 44(9) (2007) 1233-1247.

19. F. P. Agterberg, Q. Cheng, A. Brown et al., Multifractal modeling of fractures in the Lac du Bonnet batholith, Manitoba, Comp. Geosci. 22(5) (1996) 497-507.

20. T. Takemura, Multifractal analysis of microcracks in granitic rocks, J. Jpn. Soc. Eng. Geol. 40(1) (1999) 14-24 (in Japanese with an English abstract).

21. F. San José Martínez, M. A. Martín, F. J. Caniego et al., Multifractal analysis of discretized X-ray CT images for the characterization of soil macropore structures, Geoderma 156(1) (2010) 32-42.

22. J. De Souza and S. P. Rostirolla, A fast MATLAB program to estimate the multifractal spectrum of multidimensional data: Application to fractures, Comp. Geosci. 37(2) (2011) 241-249.

23. J. Paz-Ferreiro, M. D. A. Marinho, L. F. S. da Silva et al., The effects of bulk density and water potential on multifractal characteristics of soil penetration resistance microprofiles measured on disturbed soil samples, Vadose Zone J. 12(3) (2013) 1-13.

24. S. Serrano, F. Perán, F. J. Jiménez-Hornero et al., Multifractal analysis application to the characterization of fatty infiltration in Iberian and White pork sirloins, Meat Sci. 93(3) (2013) 723-732.

25. T. Sun and L. Liu, Delineating the complexity of $\mathrm{Cu}-\mathrm{Mo}$ mineralization in a porphyry intrusion by computational and fractal modeling: A case study of 
the Chehugou deposit in the Chifeng district, Inner Mongolia, China, J. Geochem. Explor. 144 (2014) $128-143$.

26. F. Luz, A. Mateus, J. X. Matos et al., Cu-and Znsoil anomalies in the NE border of the South Portuguese Zone (Iberian Variscides, Portugal) identified by multifractal and geostatistical analyses, Nat. Resour. Res. 23(2) (2014) 195-215.

27. H. Millán, R. Cumbrera, and A. M. Tarquis, Multifractal and Levy-stable statistics of soil surface moisture distribution derived from 2D image analysis, Appl. Math. Model. 40(3) (2016) 2384-2395.

28. L. Rodríguez-Lado and M. Lado, Relation between soil forming factors and scaling properties of particle size distributions derived from multifractal analysis in topsoils from Galicia (NW Spain), Geoderma 287 (2017) 147-156.

29. S. Ogura, Multifractality and time dependence of pattern formation of "suminagashi", Master Thesis, Department of Physics, Chuo University (2009) (in Japanese).

30. D. H. Sharp, An overview of Rayleigh-Taylor instability, Physica D 12 (1984) 3-18.

31. S. K. Ghosh, A. K. Pandey, P. Pandey et al., Soft-sediment deformation structures from the Paleoproterozoic Damtha Group of Garhwal Lesser Himalaya, India, Sediment. Geol. 261 (2012) 76-89.

32. T. Terada, R. Yamamoto and T. Watanabe, Experimental studies on colloid nature of Chinese black ink. Part I, Sci. Pap. Inst. Phys. Chem. Res. 23(482) (1934) 173-184.

33. H. Takayasu, Fractals in the Physical Sciences (Manchester University Press, New York, 1990).

34. M. Jinguuji and Y. Nakashima, The liquefaction positional investigations and those estimations along lower reaches of Tone River, GSJ Interim Rep. 66 (AIST14-G63166) (2014) 319-342 (in Japanese with English figure captions).

35. A. Block, W. Bloh, T. Klenke et al., Multifractal analysis of the microdistribution of elements in sedimentary structures using images from scanning electron microscopy and energy dispersive $\mathrm{X}$ ray spectrometry, J. Geophys. Res. 96(B10) (1991) 16223-16230.

36. S. Xie, Q. Cheng, X. Xing et al., Geochemical multifractal distribution patterns in sediments from ordered streams, Geoderma 160(1) (2010) 36-46.

37. S. Schlüter, U. Weller and H. J. Vogel, Segmentation of X-ray microtomography images of soil using gradient masks, Comp. Geosci. 36(10) (2010) 12461251.

38. Y. Nakashima, The use of sodium polytungstate as an X-ray contrast agent to reduce the beam hardening artifact in hydrological laboratory experiments, J. Hydrol. Hydromech. 61(4) (2013) 347-352.

39. Y. Inoue, T. Shiba, M. Ono et al., Evaluation of two-component fluid mixing pattern by multifractal analysis, Kagaku Kogaku Ronbunshu 33(2) (2007) 85-91 (in Japanese with an English abstract and English figure captions).

40. S. Hasegawa, K. Nishihara and H. Sakagami, Numerical simulation of mixing by Rayleigh-Taylor instability and its fractal structures, Fractals 4(3) (1996) 241-250.

41. K. R. Sreenivasan, Fractals in fluid mechanics, Fractals 2(2) (1994) 253-263.

42. J. J. Luque, A. Gomez and A. Cordoba, Multifractal analysis of adsorbate in a catalyzed surface reaction, Fractals 12(2) (2004) 171-177.

43. E. Perfect, A. M. Tarquis and N. R. A. Bird, Accuracy of generalized dimensions estimated from grayscale images using the method of moments, Fractals 17(3) (2009) 351-363.

44. H. Zhou, E. Perfect, B. G. Li et al., Effects of bit depth on the multifractal analysis of grayscale images, Fractals 18(1) (2010) 127-138.

45. H. Zhou, E. Perfect, Y. Z. Lu et al., Multifractal analyses of grayscale and binary soil thin section images, Fractals 19(3) (2011) 299-309.

46. F. J. Jiménez-Hornero, A. B. Ariza-Villaverde and E. G. de Ravé, Multifractal description of simulated flow velocity in idealised porous media by using the sandbox method, Fractals 21(1) (2013) 1350006. 